\title{
A New Class of Curves of Rational B-Spline Type
}

\author{
Mohamed ALLAOUI ${ }^{1}$, Jamal ADETOLA ${ }^{2}$, Wilfrid HOUEDANOU ${ }^{3}$, and Aurélien \\ GOUDJO ${ }^{4}$
}

${ }^{1}$ Département de Sciences économiques, Université de Comores, Comores

${ }^{2}$ Université Nationale des Sciences, Technologie, Ingénierie et Mathématiques (UNSTIM), Bénin

${ }^{3}$ Universite d'Abomey-Calavi

${ }^{4}$ Université d'Abomey-Calavi

September 25, 2021

\begin{abstract}
A new class of rational parametrization has been developed and it was used to generate a new family of rational $\mathrm{k}$ functions B-splines which depends on an index $\alpha[?]$ ]-[?] , $0[$ [?] ]1, +[?][. This family of functions verifies, among other things, the properties of positivity, of partition of the unit and, for a given degree $\mathrm{k}$, constitutes a true basis approximation of continuous functions. We loose, however, the regularity classical optimal linked to the multiplicity of nodes, which we recover in the asymptotic case, when $\alpha$ - [?]. The associated B-splines curves verify the traditional properties particularly that of a convex hull and we see a certain "conjugated symmetry" related to $\alpha$. The case of open knot vectors without an inner node leads to a new family of rational Bezier curves that will be separately, object of in-depth analysis.
\end{abstract}

\section{Hosted file}

AJHG.pdf available at https://authorea.com/users/436444/articles/538751-a-new-class-ofcurves-of-rational-b-spline-type 